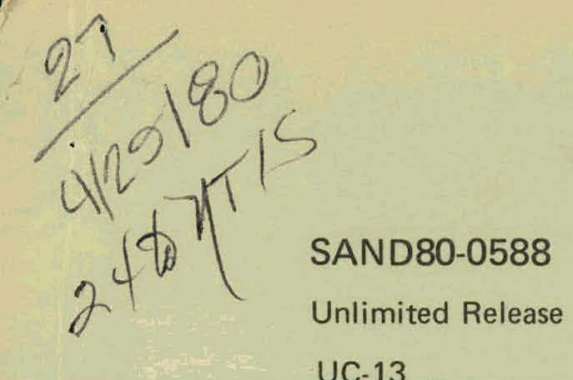

UC-13

\title{
An Investigation Into Interactive Graphics Data Base Exchange Via Gerber Data
}

\section{MASTER}

Robert E. Parks

Prepared by Sandia Laboratories. Albuquerque, New Mexico 87185

and Livermore, California 94550 for the United States Department

of Energy under Contract DE-AC04-76DP00789

Printed March 1980

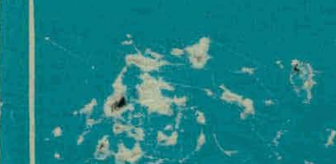

\section{(17) Sandia National Laboratories}




\section{DISCLAIMER}

This report was prepared as an account of work sponsored by an agency of the United States Government. Neither the United States Government nor any agency Thereof, nor any of their employees, makes any warranty, express or implied, or assumes any legal liability or responsibility for the accuracy, completeness, or usefulness of any information, apparatus, product, or process disclosed, or represents that its use would not infringe privately owned rights. Reference herein to any specific commercial product, process, or service by trade name, trademark, manufacturer, or otherwise does not necessarily constitute or imply its endorsement, recommendation, or favoring by the United States Government or any agency thereof. The views and opinions of authors expressed herein do not necessarily state or reflect those of the United States Government or any agency thereof. 


\section{DISCLAIMER}

Portions of this document may be illegible in electronic image products. Images are produced from the best available original document. 
Issued by Sandia Laboratories, operated for the United States Department of Energy by Sandia Corporation.

\section{NOTICE}

This report was prepared as an account of work sponsored by the United States Government. Neither the United States nor the Department of Energy, nor any of their employees, nor any of their contractors, subcontractors, or their employees, makes any warranty, express or implied, or assumes any legal liability or responsibility for the accuracy, completeness or usefulness of any information, apparatus, product or process disclosed, or represents that its use would not infringe privately owned rights. 


\title{
SAND 80-0588
}

Unlimited Release

Printed March 1980

\author{
AN INUESTIGATION INTO INTERACTIVE GRAPHTCS \\ DATA BASE EXCHANEE \\ UIA \\ GERBER DATA \\ $\Xi$
}

BY R. E. PARKS

COMPUTER AIDS SYSTEMS DEVELOPMENT

DIUISION 2424

CONSUL TANT

K. E. WIEGANDT

COMPUTER AIDS SYSTEMS DEVELOPMENT

DIVISJON 2424

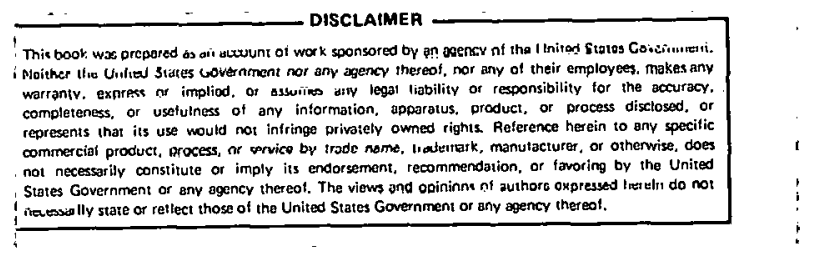




\section{CDNTENTS}

1. O INTRODUCTION

Page

4

2. 0 2D CGERBER\% ID 4

2. 1 File Selection 4

2. Process Planning 4

2. 3 Gerber prorpssing 6

2. 4 Creating a Diak File 7

2. 5 Gerber Deformating 7

3. O DRTGINAL VS. NEW FILE 7

3. 1 Definitions and Placements 9

3.1.1 FX Definition 9

a. 1.2 S1 Definition 11

3. 1.3 SE Definition Il

3.1. 4 Cell Definition 11

3. 1. 5 Polygon Definition 11

3. 1.6 Path Definition 11

3. 1.7 ArE Definition 12

3.1.日 Text 12

3. 2 File Size 12

4. 0 2D CQERBER $3 D \quad 12$

5. 0 JD CQERBER 2D 15 
b. O SUMMARY

$-3-$ 
Data representing the same interactive graphic design varies "greatly from one graphic system manufacturer to another. Therefore, translating the data into a common form to effect data base exchange is a difficult problem.

This study examines the use of the Gerber language as a common data from into which the design data could be written and exchanged between unlike systems. However, for the purpose of this study only one manufacturer's system was used. This system, an Applicon Graphic System (AGS), was used to cyclically check retention or degeneration of the data integrity, when the orjginal design was extracted/defined in the Gerber language and reentered into the AGS utilizing various Gerber Interface Programs: The various parts of this study include the transferring of data not only in the eD environment. but eD to $3 D$ and 30 to $2 D$

\section{2. $0 \quad 2 D$ CGERBER $2 D$}

Realizing that GERBER is a 20 vector plot/aperture flash language, the first transfer examined was that of an AGS/870 ( $2 D$ ) data base. The procedure involved in processing and comparison of the files is described in the following paragraphs.

\section{1 File Selection}

The file selected for procegsing was a tupicial AGS/870 (2D) mechaniral definition. This was not to slight the AGS/G70 electrical, but should point out problem areas (if any) for hoth tupes of definitions. Since it is well known that the portion of the data representing circuit paths and terminal areas (photo plotted data) can be tansferred via the Gerber language, we will concentrate on the rest of the data contained in the data base. This portion of the datal such as collective components (celis), dimensions, notes, and any other information, is a vital part of what makes a TOTAL data base. See figure 2-1 for plot of the original data hase.

\section{P Process Planning}

Before Gerber data was obtained, consideration was given to processing data which was not typically processed and handling the level separation which is an integral part of the data base. Not only was every entity of the data base tu be processed, hut returned to the level on which they were originally defined when the Gerber data was reentered to form a resultant data base.

There are sixteen levels for component definition and 


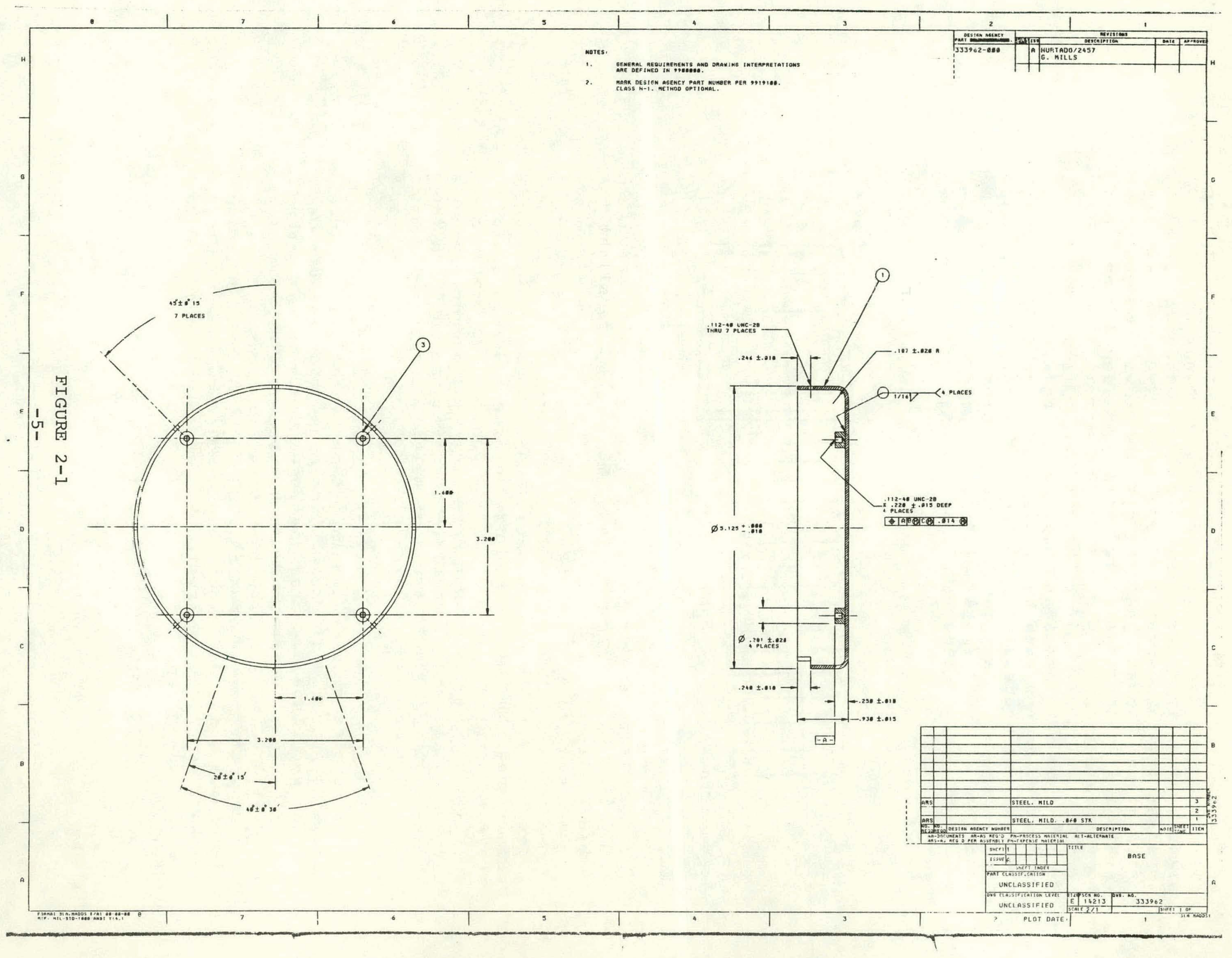


separation in the ACS data base. An entity may be defined on any one, all, or any combination of the sixteen levels. Each level can be thought of as a separate drawing sheet. See Figure $2-2$ for graphic explanation. Most graphic systems have some sort of level separation, especially ones considered for this type of exchange.

Each entity or component type also had to be given consideration for each had to be associated with a gerber aperture for processing and reentered into a resultant data base with as many of its original attributes as possible. Each of these will be discussed in detail later in this study (section 3) when comparisons are made.

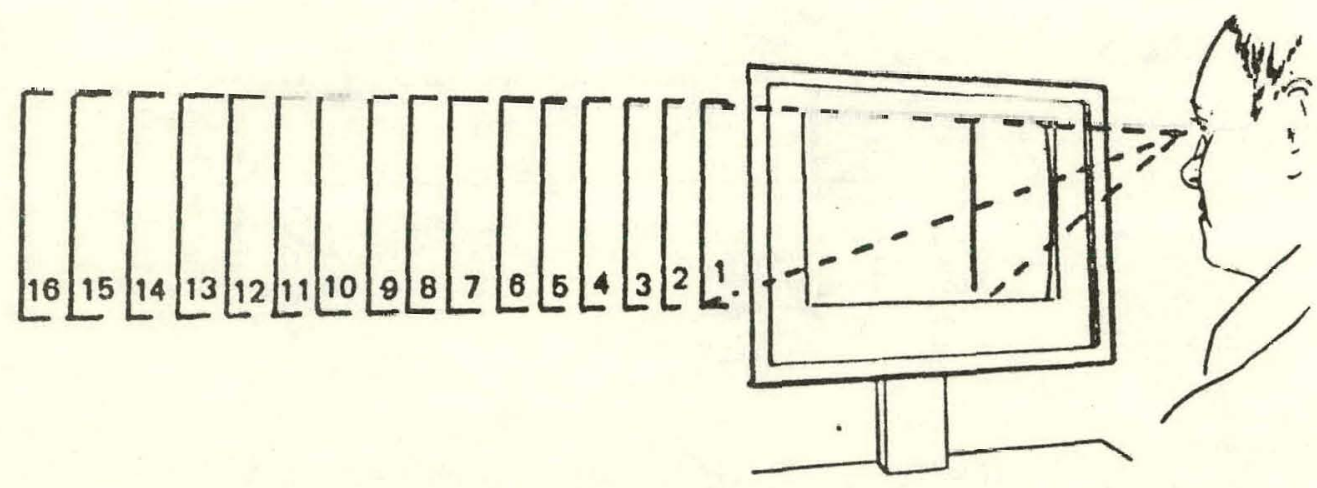

Figure 2-E - The 16 Drawing Level

\section{3 Gether Processing}

Processing the original data into Gerber data was accomplished by utilizing one of the AGS Input/output interface programs, I033. I033 is designed to interface the AGS to Various Gerber Scieritific Instrument Companu systems. It yenerates complete plotting instructions for input to the photoplotter controller. Butput media may be 7-or 9-track magnetic tape, disk file structure, or on-1 ine.

Al this point process planning came into play, since processing for level separation means that in some way data for each level must be distinguishable in the Gerber data. This was accomplished by displaying and processing one level at a time, which for this application, meant five separate executions of I0;3. For a printed wiring board application additional executions would be required to include circuit levels as explained under File Selection (paragraph 2.1 ). 
Processing was done in an off-line mode since that would be the method most likely used in transferring data between systems. For a complete Gerber listing and verifying plot (made via a Xynetics plotter under Gerber emulation), see Appendices.

\section{4 Creating a Disk File}

Since the media use in transferring Gerber data would, most likely, be magnetic tape a disk file of the data must be created for eventual deformatting sexplained later). To create a disk file of Gerber data another AGS interface program I070 (IN/QUT) was utilized. I070 allows the AGS user to transfer data from I/0 devices to the AGS file structure and vice versa. It will also perform code conversions such as BCD to ASCII. These features were utilized in creating a disk file of Gerber data.

\section{5 Gerber Deformatting}

With an AGS design file loaded into the working area of the disk, which contains the appropriate library of components, deformatting may be accomplished. This again was accomplished $v i a$ an AGS interface program, I071 (GERBIN). IO71 allows the AGS uset to create an AGS drawing file from a Gerber format plotter disk file. The user transfers his or her plot data from magnetic tape to disk, as previously explained, then constructs the library of components to match aperture sizes as required. IO71 then can be, and was in this study, executed referencing the previously created Gerber data file.

Level separation must again be commented on, since this is the point in which the sequence of Gerber commands are separated back into the appropriate levels. There is a limit of five such sequence distinctions that can be made in any one execution of I071. This is not to say that five is the maximum number of levels which can be deformatted, but does point out that Gerber data for more than five levels must be broken into separate disk files and I071 must be executed more than one time. This brings us back to the printed wiring application as this would most likely be the rase for those applications.

Once the deformatting was accomplishod again a plot was made of the resultant file. See Figure 2-3.

\section{O DRIGINAL VS. NEW FILE}

The file generated by I071 (Fig. 2-3) is very similar in outward appearance to that of the orignal file ifig. 


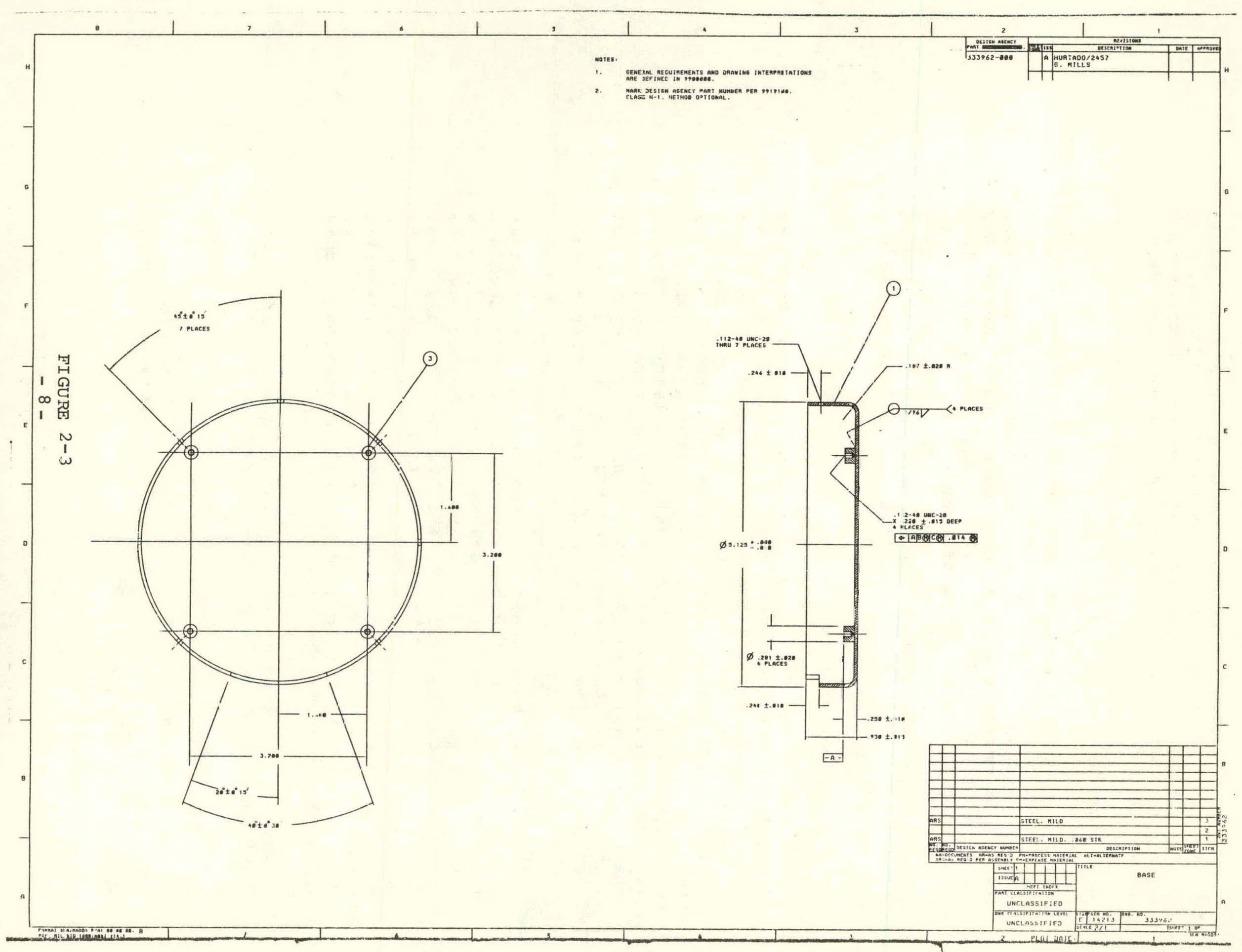


2-1). There are two obvious differences, 1) the lack of arrowheads, and 2$)$ the lack of dashed center lines. However, there are many differences which are not apparent when looking at the plots.

To obtain a summary of the actual differences between the files. APPLE data was generated for both files. APPLE is a form to which an AGS file can be translated, so that it may be read and/or processed by large programs resident on a host computer. It was through a small utility and one of the programs, that the APPLE data was processed and a summary of the definitions and placements obtained (see Figs. $3-1$ and $3-2$ ). It is in this area where the differences ocrut.

\section{1 Definitions and Placements}

An AGS drawing file has a library of component definitions which may include the following types:

\section{FX - Fixed dimensioned components \\ S1 - Components stretchable in one dimension \\ Se - Components stretchable in two dimensions \\ POLY - Broken lines or a series of vertices joined together bu lines}

PATH - Polygons with width or linetypes (e.g. metal runs or leader and centerlines)

ARC - Arcs and full circles

CELL - Components consisting of any combination of the above types

Placements of any of the component tupes listed may appear in the drawing portion of an AGS file. Individual definitions and their placements as they pertain to the files are described in the following paragraphs (refer to Figs. $3-1$ and $3-2$ ).

\section{1. 1 FX Definition}

There are 22 definitions of the FX type and one placement of that type in the original file. Since this was a zero length definition (used to attach text for notes) it was not processed into the Gerber dato and, therefore; does 
$29-406-79$ 16:25:00

APPLE FILE NAME: [WIEGANDTJORIGFILE. DAT

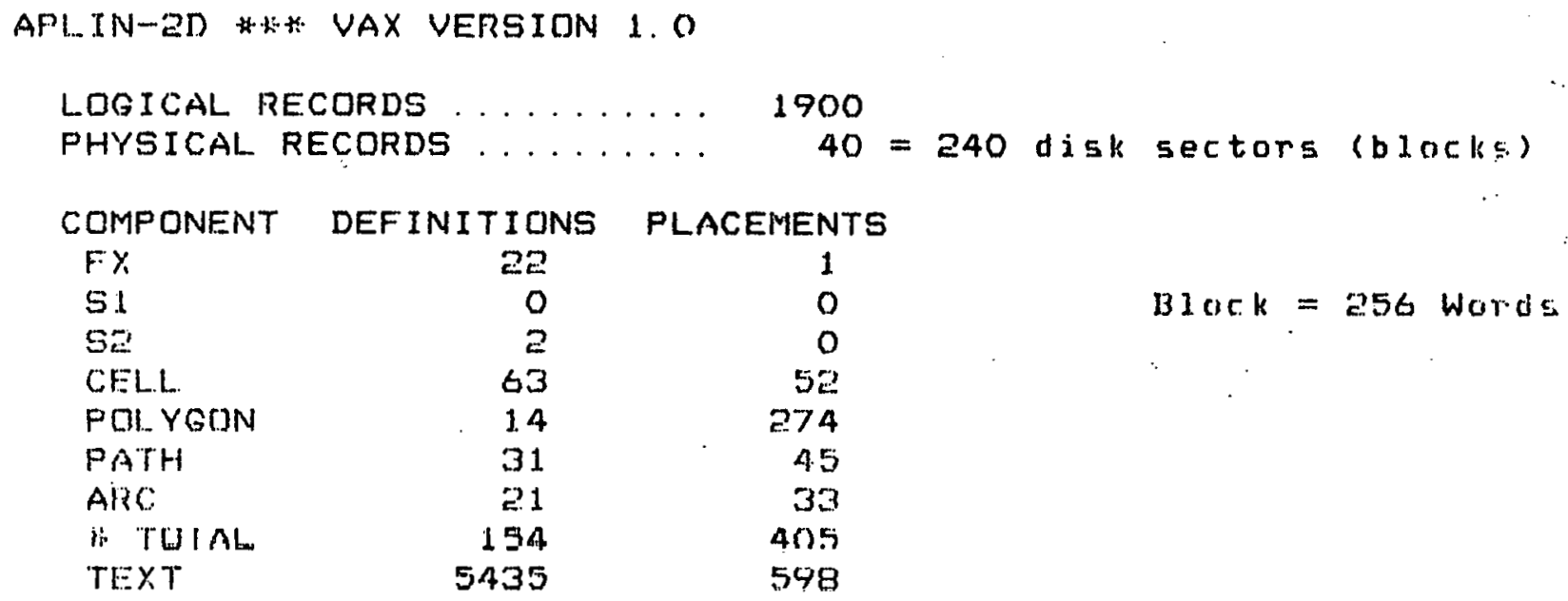

FHLE TYPE ,.... PWEOSH

FILE VERSTON ... 49

FIGURE $3 \cdots 1$

20-AUO-79 16:23: 39

APPLE FILE NAME: [WIEGANDTJNEWF ILE. DAT

APLINN-ED \#H: VAX VERSION 1.O

LOGICAL RECORDS ......... 2554
PHYSICAL RECORDS ....... $55=330$ disk sectoTs (blocks)

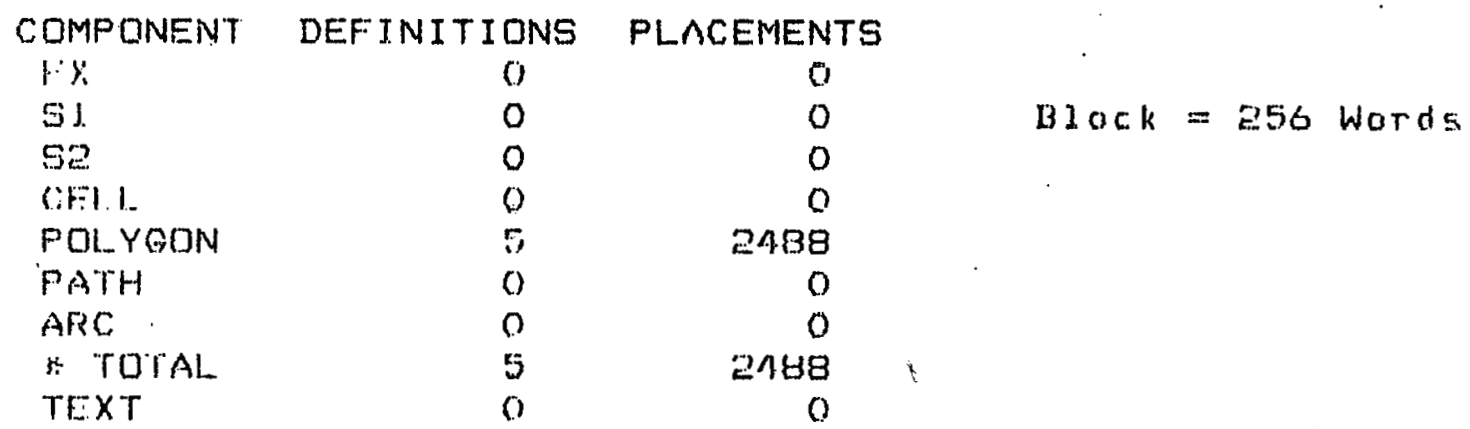

FILE TYPE ..... GBNOAA

FILE VERSIION ... 3 
not appear in the new drawing file.

\section{1. 251 Definition}

No definitions of this type were contained in either file.

\section{1. 3 Se Definition}

Two definitions of this type were contained in the library of the original file, but none were placed. For this reason none appear in the new file.

\section{1. 4 Cell Definition}

In the original file there were 63 definitions of this type, resulting in 52 placements of one or more cell components. None are reflected in the new drawing file. This is the case, because Gerber data is a series of draft functions and no longer can constituent parts be grouped, as belonging to a particular component definition.

This is a very important difference between the files, since no longer may the original group of individual components be added or modified as a unit. In the case of the drawing format, variable text fields used to enter such information as issue, drawing number, part number, and classsification, no longer exist. For these same reasons reference designations and connectivity information would no longer be associated with the components, if this procedure were applied to an electrical definition (PWB or schematic). This implies that circuit analysis is no longer possible for the resulting definition.

\section{1. 5 Polygon Definition}

In the original file there were 14 separate polygon definitions and 274 placements of those polygons. The new file contains only five polygon definitions, because it uses only five. The five polygon definitions use those created under the naming and level conventions of I071 (one per level utilized). The number of placements increased indicating the loss of other component types.

\section{1. G Path Definition}

The path definitions contained number 31 and placements of one or more of this type component, number 45 in the original file. The path type components placed in this mechanical definition are of the line type variety. This type of path is used in displaying leader lines and 
centerlines. Because the line type path is described to the system by coded component name and 1071 has its own naming convention, none are defined or placed in the new file. This is the reason for the obvious loss of arrowheads and dashed centerlines mentioned previously.

\section{1.7 Arc Definition}

Arc definitions number 21 in the original file and placements 33 . I033 processes these arcs as a series of straight line segments unless they are described in the component specifications (described earlier) as a flash aperture. In order for this to be accomplished each and every diameter would have to be included in the specifications. This was not done, therefore, there are no arc definitions or placements in the newly generated file. Fig. 3-3 illustrates the straight line segments by showing a select butterfly at each vertex of the pulygon opptoximation.

\section{1. 8 Text}

Another very important difference between the original and newly generated files is text. Text such as drawing notes, dimensions, and format text is very easily changed via the edit text mode. The summary of definitions and placements shows that there are 5435 text characters associated with component definitions (text within a cel1) and 598 text characters placed in the drawing. In contrast to this nio text characters appear in the newly created file. As a result of I071, all text characters appear as polygons representing the plotted AGs text characters. Fig 3-4 illustrates the characters as they are now made up of polygons rselect butterflies at polygon vertices). This text would have to be deleted and replaced to use the text editing features of any system.

\section{2 File Size}

Another item which must be pointed out at this time is that of file size. The resulting file has been increased significantly in size. The original file size was 240 disk blocks as compared to 330 disk blocks for the file resulting from this procedure. This is a significant change affecting both file manipulation and handing.

\section{0 2D CGERBERУ 3D}

The second phase of the study to be performed was that of building an AGS/880 (3D) file from the Gerber data generated from the original AGS/870 (ED) file. This was accomplished by using I020, the NC Verify interface, to 


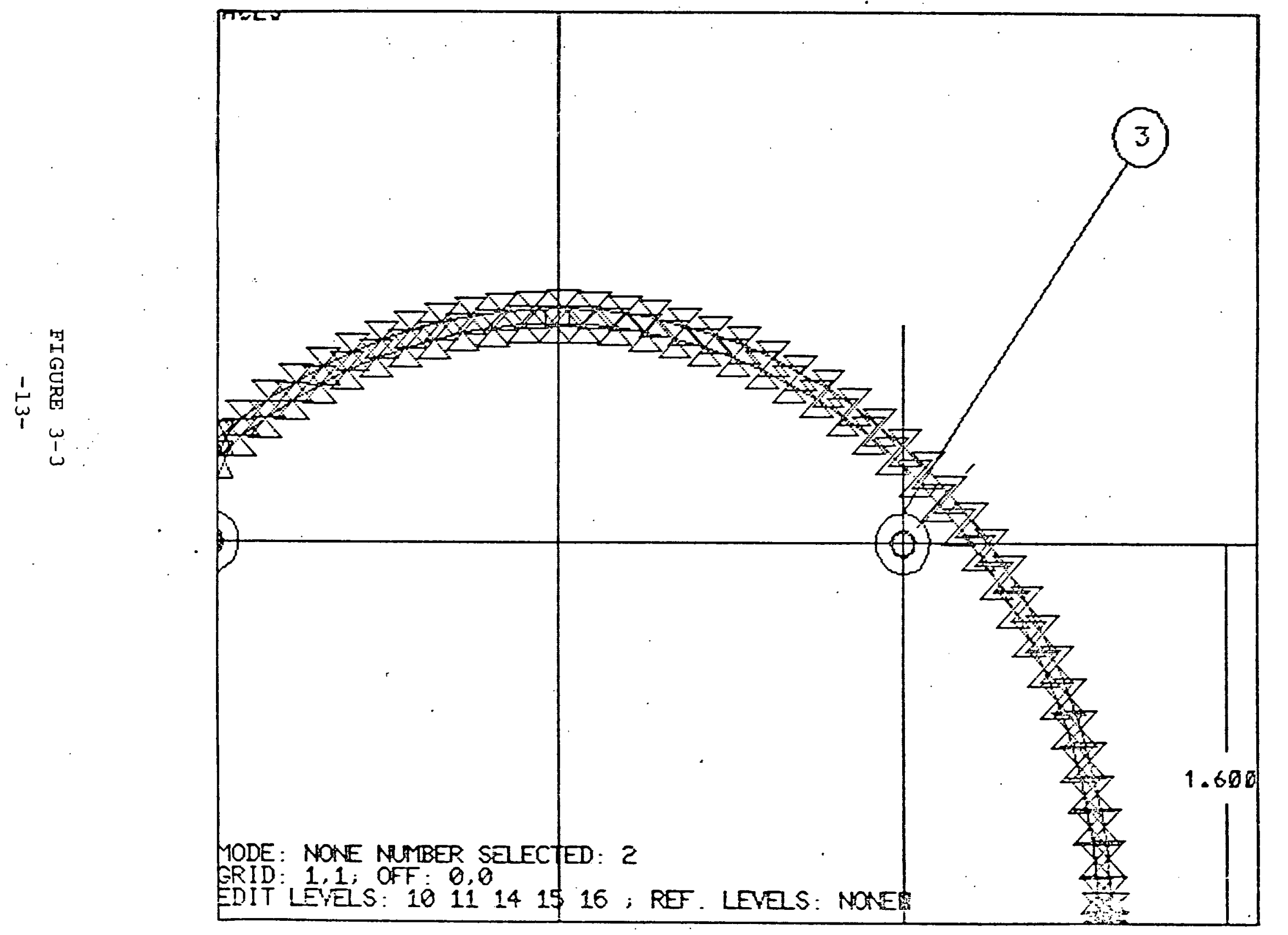




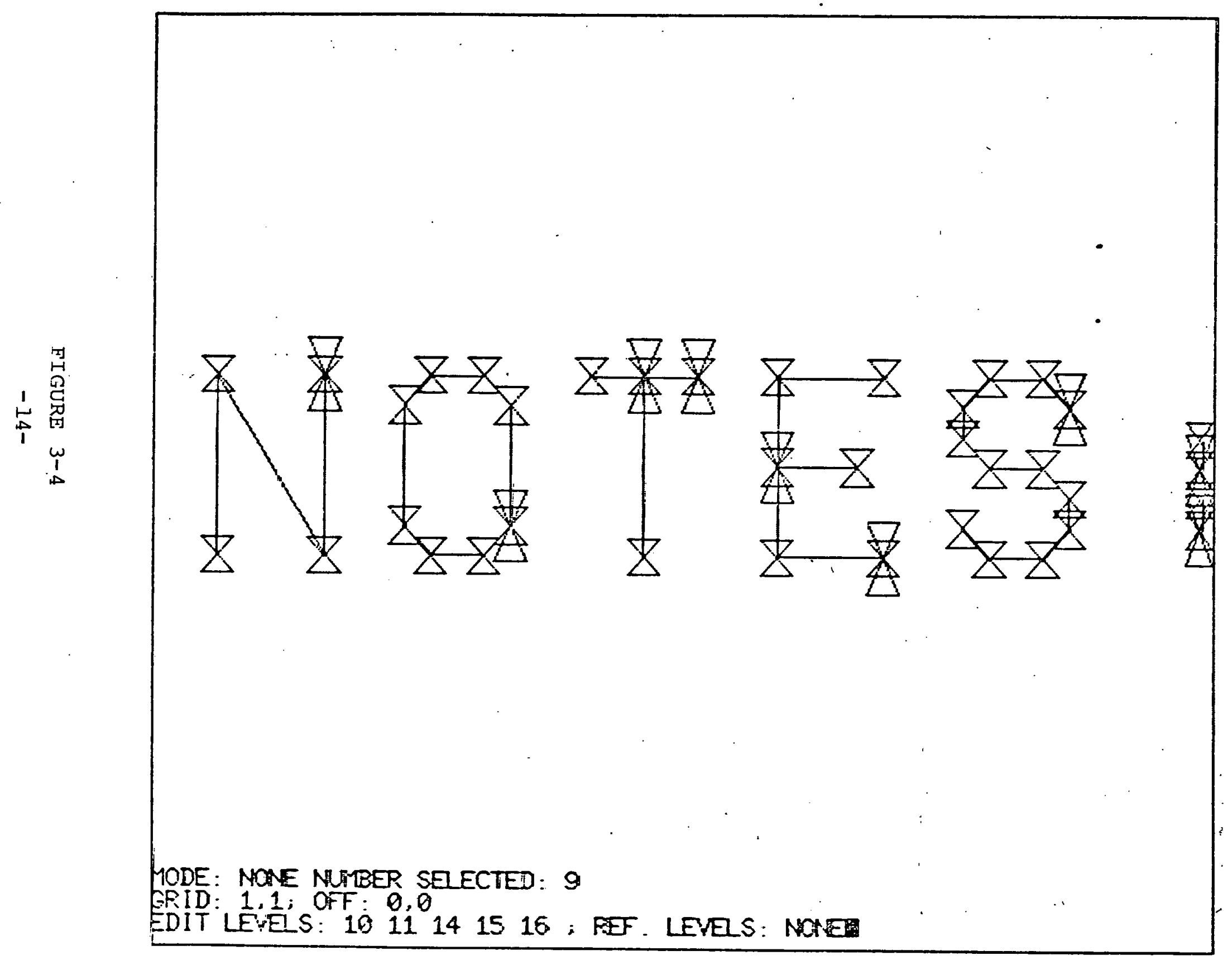


deformat the Gerber data into an AGS/880 file. ID2O is an interface program supplied by Applicon whose primary purpose is to verify NC machine tapes. The resulting AGS/880 data base was found to have all of the limitations displayed in its AGS/870 counterpart. In addition, no viable method was found to effect level separation. This was due to the inability of Iozo (primarily an NC program) to distinguish levels by either sequence, as in I071, or Gerber aperture selects which might be present in the Gerber data file.

5. 030 CGERBER $2 D$

The processing of an AGS/Bgo file was the last phase of the study to be investigated. Due to the fact that no Gerber interface exists for the AGS/B80 system, the NC interface IO2, NC Programming Package, was investigated. No viable method was found to exract Gerber data which would equal that of I033, an AGS/870 Gerber Interface.

6. O SUMMARY

Even though plots of the files appear very similar, the individual data bases are very dissimilar. Programs, both present and future, which might supply needed information or design aids and characteristics, would find it virtually impossible to do so from a data base lacking the sophistication and completeness of the original AGS data base. Man-machine hours required to bring the data base back to original quality would be extensive, approaching that of digitizing a plotted or manualiy prepared drawing into the AGS. The database is now strictly a "PLOT FILE". Plot files contain geometry. but not topology/associativity. Consequently. no simulation or analysis requiring geometric associativity and attribute information (circuit analysis) can be performed on the resultant file.

The loss of data base integrity shown by this study was restricted to an AGS to AGS transfer. The loss could very easily be magnified if the transfer were between unlike systems. 
Distribution:

The Bendix Corporation

Kansas City Division

P. D. Box 1159

Kansas City, Missouti 64141

Attn: D. Lambeth

D. Whiteman, DOE/ALO

G. Mahfouz, MOUND

L. Turner, MOUND

T. Repke, GEND

2420 R. W. DeVore

2424 Libraty (10)

2424 Gino Carli

2424 Software Coordinator

2424 W. C. Burd

$24: 34$ C. Kellu

2424 R. E. Parks

2424 Lee Tolivet

2424 K. E. Wiegandt

2450. A. R. Eiffert

2454 G. R. Urish

2457 R. E. Thompson

3151 W. L. Garner (3)

for DOE/TIC (unlimited release)

8274 F. F. Eichert Jr.

3154-3 R.P. Campbell for DOE/TIC (25)

3141 T. L. Werner (5) 


\section{APPENDICES}

A-1 Verifying Plot Made from Gerber Data

A-2 Listing of Gerber Data (Micto Fiche) 


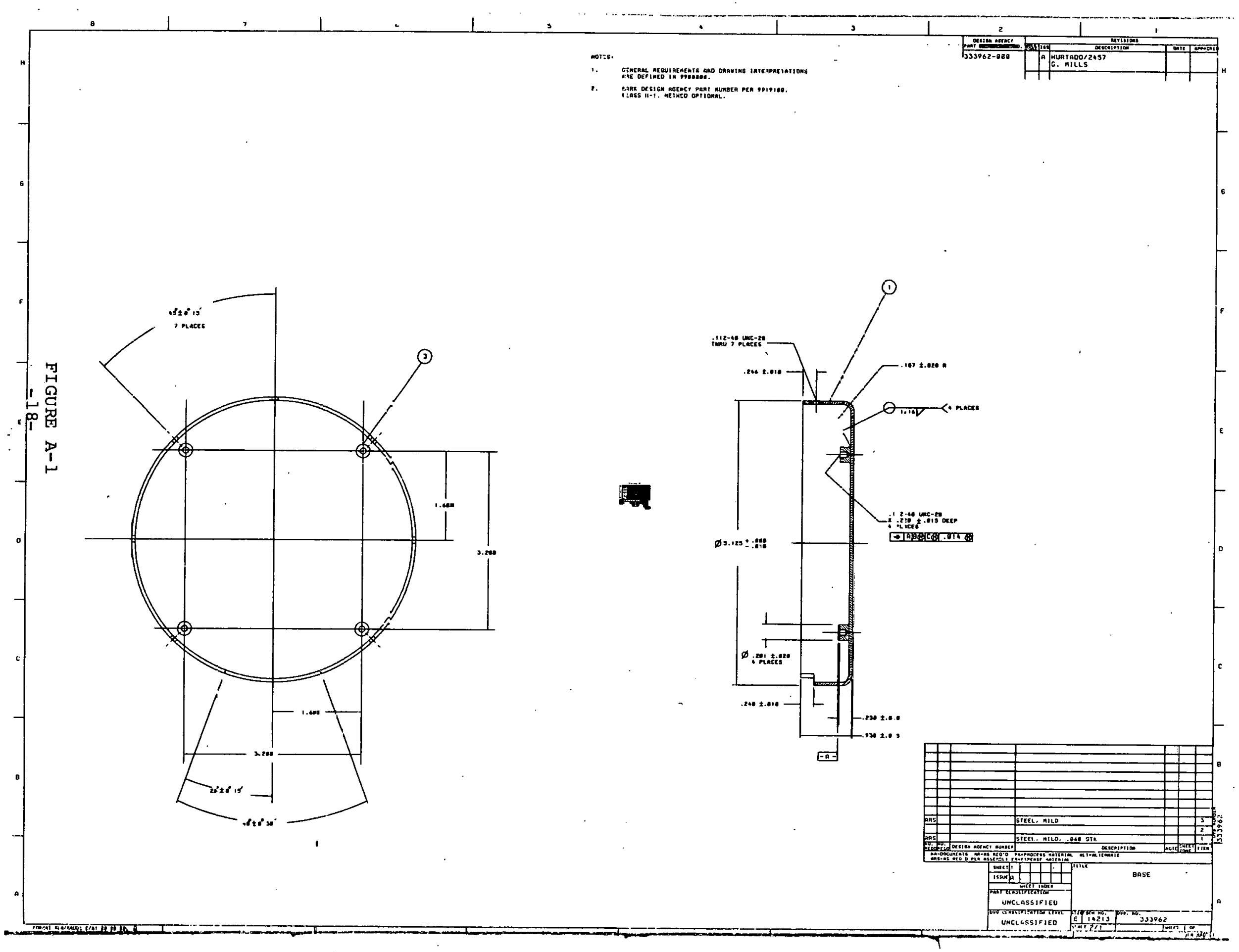


